\title{
Evaluation Of Gas-Chromatography With Electrolytic Conductivity Detection And Electron-Capture Detection And Use Of Negative Chemical Ionization Gc-Ms For The Analysis Of PCBS In Effluents
}

\author{
J Greaves \\ Virginia Institute of Marine Science \\ E Harvey \\ Virginia Institute of Marine Science \\ RJ Huggett \\ Virginia Institute of Marine Science
}

Follow this and additional works at: https://scholarworks.wm.edu/vimsarticles

Part of the Environmental Sciences Commons

\section{Recommended Citation}

Greaves, J; Harvey, E; and Huggett, RJ, "Evaluation Of Gas-Chromatography With Electrolytic Conductivity Detection And Electron-Capture Detection And Use Of Negative Chemical Ionization Gc-Ms For The Analysis Of PCBS In Effluents" (1991). VIMS Articles. 1493.

https://scholarworks.wm.edu/vimsarticles/1493 


\title{
EVALUATION OF GAS CHROMATOGRAPHY WITH ELECTROLYTIC CONDUCTIVITY DETECTION AND ELECTRON CAPTURE DETECTION AND USE OF NEGATIVE CHEMICAL IONIZATION GC-MS FOR THE ANALYSIS OF PCBS IN EFFLUENTS
}

\author{
John Greaves, * Ellen Harvey and Robert J Huggett \\ Virginia Institute of Marme Science, School of Marine Science, \\ College of William and Mary, Gloucester Point, Virgını 23062
}

(Recelved 26 January 1991, Accepted 15 April 1991)

\begin{abstract}
Gas chromatography with electrolytic conductıvity detection and electron capture detection in combination with gas chromatography-mass spectrometry, operated in the electron capture negative chemical ınization mode, were evaluated as techniques for the analysis of polychlormated biphenyls in wastewater from an industrial facility The specificity of the electrolytic conductivity detector reduced sample turnaround time because extracts could be analyzed without fractionation or cleanup Using a 2 L sample, this methodology had a quantification limit, based on Aroclor 1260, of $01 \mu \mathrm{g} / \mathrm{L}$ and a detection limit of approximately $003 \mu \mathrm{g} / \mathrm{L}$ The electron capture detector was subject to interferences from nonhalogenated compounds and required additional sample cleanup Electron capture negatıve chemical ionization gas chromatography-mass spectrometry was highly specific and provided full mass spectra of polychlorinated biphenyl congeners at the same quanti fication limit Effluents from the facility had polychlorinated biphenyl concentrations of 01 to 1 $\mu \mathrm{g} / \mathrm{L}$
\end{abstract}

Keywords-Gas chromatography Electrolytic conductivity detector
Polychlonnated biphenyls Wastewater Electron capture negatıve chemical ionızation GC MS

\section{INTRODUCTION}

Polychlorinated biphenyls (PCBs) are stable compounds that have had many industrial and commercial applications The stability of these compounds has resulted in their becoming persistent environmental pollutants that have a wide variety of biological effects [1] Although production of PCBs in the United States was banned in 1977 [2], usage of PCBs in closed systems has contin ued This means that in addition to PCBs already present in the environment, there has been a potentral for further releases of PCBs due to industrial accidents

The analysis of PCBs requires specific and sen sitive techniques Gas chromatography (GC) with electron capture detection has been the instrumen-

*To whom correspondence may be addressed

Contribution No 1674 from the Virginıa Institute of Marine Science, College of Wilham and Mary tation most frequently used due to its sensitivity to halogenated organic compounds The electron capture detector (ECD) has low maintenance requirements and necessitates only limited operator experience Though often considered to be a specific detector, the ECD does respond to nonhalogenated compounds For example, compounds containing oxygen, sulfur, and nitrogen have electron capturing characteristics, and although sensitivities to these elements are much lower, their presence at high concentrations in environmental samples may overwhelm the detector, which could lead to interferences and false positives during analyses

The electrolytic conductivity detector (ELCD) may be used as an alternative for the detection of organohalides Because the ELCD can be configured so only halogens are detected, it is a more specific detector than the ECD Instrument specifications indicate that the ELCD is approximately 10 times less sensitive than the ECD (OI Analytical, College Station, TX, a:ld Varian Instruments, Walnut 
Creek, CA). However, the higher specificity of the ELCD makes it particularly useful whenever the increased sensitivity of the ECD is not essential.

The operation of the ELCD is based on the catalytic reduction, with hydrogen, of an analyte at high temperature (e.g., $950^{\circ} \mathrm{C}$ ) in the presence of nickel. The formed hydrohalogen acid (in the case of PCBs it is hydrochloric acid) is assayed by measurement of the conductivity changes it produces when dissolved in an electrolyte.

The response of the ELCD is directly proportional to the number of halogen atoms present in a molecule, regardless of structure, which is a particularly useful aspect of this detector when compared with the ECD $[3,4]$. In the latter, isomeric structure influences detector response significantly. This makes quantification with the ECD, particularly for application such as PCB congener analysis, more difficult because response factors differ for each congener [3]. For the ELCD in the same type of analyses, only 10 response factors are required, one for each level of chlorination [4].

Gas chromatography-mass spectrometry (GCMS) is the technique of choice for the positive identification of volatile and semivolatile organic compounds with molecular weights of less than approximately 1,000 $\mathrm{Da}$. Conventional electron ionization-(EI-) GC-MS does not possess the necessary sensitivity or specificity to provide full mass spectra of organohalides such as PCBs at typically encountered environmental concentrations. However, electron capture negative chemical ionization(ECNCI-) GC-MS can provide both the sensitivity and the specificity [5] necessary for full spectra for positive identification of compounds. A mass spectrometric technique that improves sensitivity and is independent of the mode of ionization is selected ion monitoring. However, this technique must be used with caution because full spectral confirmation is not obtained, leaving potential for false positives due to interfering compounds.

In this report, GC-ELCD and GC-ECD, in combination with ECNCI-GC-MS, are evaluated in terms of sensitivity, specificity, and sample turnaround time as techniques for monitoring PCBs in the effluent from an industrial facility.

\section{MATERIALS AND METHODS}

Aroclors 1260 and 1254 and hexabromobiphenyl were obtained from Ultra Scientific (North Kingstown, RI). Solvents were Burdick and Jackson high-purity solvents (Baxter Healthcare Corp., McGaw Park, IL). Nitrogen (prepurified and ultra-high purity) and hydrogen (ultra-high purity) were obtained from Union Carbide, Linde Division (Danbury, CT). Helium (extra-high purity, <5 ppm total impurities) was obtained from the U.S. Department of the Interior, Bureau of Mines (Amarillo, TX).

Glassware was subjected to extensive cleaning with detergent, followed by rinsing with dilute acid and deionized water and drying with acetone. Immediately prior to use, glassware was rinsed sequentially with toluene, methanol, acetone, and dichloromethane.

Effluent samples were collected from the outfall of an industrial facility. The intake water for the ' plant was also sampled to check possible contamination in the incoming water. A trip blank, consisting of deionized water that was taken to the sampling location and exposed to the atmosphere, accompanied every set of samples. The trip blank was extracted at the same time and in the same manner (see below) as the samples with which it was associated. In addition, procedural blanks $(2 \mathrm{~L}$ deionized water) were extracted with each set of samples to confirm the absence of contamination in reagents and glassware. Recoveries of Aroclor 1260 were determined with multiple sets of replicated $(n=4)$ spiked samples as well as additional spiked samples equivalent to $10 \%$ of the number of environmental samples.

Samples were collected in 4-L amber bottles. The samples were sealed and transported on ice. Upon arrival in the laboratory, samples were either extracted immediately or stored on ice. All samples were extracted within $72 \mathrm{~h}$ of collection.

Samples were extracted in accordance with U.S. Environmental Protection Agency (EPA) methodology (method no. 625) [6], with some minor modifications. Briefly, unfiltered 2-L water samples were placed in separatory funnels and extracted three times with dichloromethane $(120 \mathrm{ml}, 2 \mathrm{~min}$ each extraction). The extracts were combined and reduced in volume by roto-evaporation to approximately $2 \mathrm{ml}$. The samples were transferred with repeated dichloromethane rinses into graduated glass tubes and reduced in volume to $0.2 \mathrm{ml}$ in a water bath at $35^{\circ} \mathrm{C}$, while purging with nitrogen. The dichloromethane was then exchanged for hexane by addition of $1 \mathrm{ml}$ hexane, followed by reducing the volume, under nitrogen, to $0.2 \mathrm{ml}$. This hexane addition and volume reduction were repeated twice to ensure complete removal of the dichloromethane.

Sample extracts containing excessive amounts of interfering compounds and those analyzed by GC-ECD were subject to cleanup by Florisil 
(Fisher Scientıfic, Pittsburgh, PA) column chromatography PCBs were eluted from a $20 \mathrm{~g}$ column of pre-extracted and activated Florisil capped with activated copper powder, using $200 \mathrm{ml}$ of $6 \%$ diethvl ether in hexane The eluates were reduced in volume to $02 \mathrm{ml}$ as descubed above

Gas chromatography was carried out on Varian Model 3300 instruments The injectors were splitsplitless, operated in the splitless mode, and main tained at $300^{\circ} \mathrm{C}$ The columns were $30-\mathrm{m}$ long, $033-\mathrm{mm}_{1} \mathrm{~d}$ fused silica coated with a $025 \mu \mathrm{m}$ film of cross linked $5 \%$ phenyl-95\% methylsilcone liquid phase (DB 5, J\&W Scientific, Folsom, CA) Helium, at a head pressure of $140 \mathrm{kPa}$, was used as the carrier gas The GC column oven con ditions were as follows initial temperature $90^{\circ} \mathrm{C}$, 1 -min hold, programmed from 90 to $300^{\circ} \mathrm{C}$ at $6^{\circ} \mathrm{C} / \mathrm{min}$, and a final temperature hold of $10 \mathrm{~mm}$ Sample injection volume was $3 \mu \mathrm{l}$ with a $1-\mu \mathrm{l}$ hex ane plug Detectors were an ELCD (Model 4420 and Model 4440, OI Analytical) and a Varian ECD The ELCD was operated in the halogen-selective mode with the nickel reaction tube at $950^{\circ} \mathrm{C}$ and a hydrogen flow rate of $100 \mathrm{ml} / \mathrm{mm}$ The elec trolyte was $n$-propanol with a flow rate of 20 to $50 \mu \mathrm{l} / \mathrm{min}$ The ECD used ${ }^{63} \mathrm{~N}$ i as the $\beta$ particle source The detector base temperatures were $300^{\circ} \mathrm{C}$ for both types of detectors The makeup gases were set at approximately $30 \mathrm{ml} / \mathrm{min}$ for both types of detectors, with ultra-high purity nitrogen being used for the ECD and helium for the ELCD The ELCD required minımal maintenance, in contrast to previous generations of this detector that required careful handling

Quantification of samples was by GC-ELCD and GC-ECD and used the external standard method Calibration curves were prepared dally from injection of 3,10, and $40 \mathrm{ng}$ of Aroclor 1260 The peak areas of the six major congeners (IUPAC numbers $138,149,153,174,180,187)$ were summed and a regression line calculated The peak areas for the same congeners in the samples were added together and concentrations determined from the regression line Results were expressed in terms of Aroclor 1260

An ELQ 400-2 quadrupole GC MS (Extrel Corp, Pitsburgh, PA), operated in the ECNCI mode with methane as the moderator gas, was used to confirm identification of the PCBs The GC conditions were as described above The GC column was introduced through the interface (maintained at $250^{\circ} \mathrm{C}$ ) up to the lon source The methane was admitted coaxially to the column The source temperature was set at $100^{\circ} \mathrm{C}$, and the electron en- ergy was $300 \mathrm{eV}$ The instrument was scanned from mass 100 to 700 at $500 \mathrm{amu} / \mathrm{s}$

\section{RESULTS AND DISCUSSION}

In the present work, ELCD and ECD detectors were compared for the quantification of PCBs present in the effluent from an industrial facility Confirmation of identities was obtained in all cases by ECNCI GC MS

Figure 1 illustrates the use of the ELCD for the detection of Aroclor 1254 (Fig 1A) and Aroclor 1260 (F1g 1B) as well as for PCBs in a wastewater effluent sample extract (Fig 1C) The extract was not subject to any purification steps prior to analysis The chromatographic profile observed for the effluent sample can clearly be seen to be the result of combining the profiles obtained for Aroclors 1254 and 1260 The results of ECD analysis are shown in Figure 2 The analysis of Aroclor 1260 (Fig 2A) gives a peak pattern similar to that obtained with ELCD (Fig 1B) Responses for the different congeners vary, however, thus giving a chromatogram with differing peak heights The lack of specificity of the ECD becomes evident when an effluent that had not been subject to Florisil chromatography is analyzed, as shown in Figure 2B The interfering compounds make it difficult to determine which components of the chromatogram can be attributed to Aroclor 1260 These interferences were removed by using Florisil column chromatography Recoveries of the PCBs from Florisil were quantitative This cleanup, followed by re analysis by GC-ECD, made it possible to match many of the peaks observed in the resulting chromatogram (Fig 2C) with those obtained for Aroclor 1260 (Fig 2A)

The quantification limit of samples analyzed on the ELCD was $01 \mu \mathrm{g} / \mathrm{L}(01 \mathrm{ppb})$, expressed in terms of Aroclor 1260 The detection limit was two to three times lower than this, approximately 003 to $005 \mu \mathrm{g} / \mathrm{L}$ Because quantification was based on Aroclor 1260 , recognition of the PCB profile was the essential factor in determining quantification and detection limits Quantification of PCB mixtures inevitably requires some compromises because of the differing concentrations of the congeners, however, the multiple peak technique used here provides necessary specificity and sensitivity The sensitivity of the ECD is greater than that of the ELCD, in the present case about a 30 fold difference was noted, rather than the 10 fold difference suggested by the manufacturer But the concentrations observed in the effluents were $\geq 01$ 

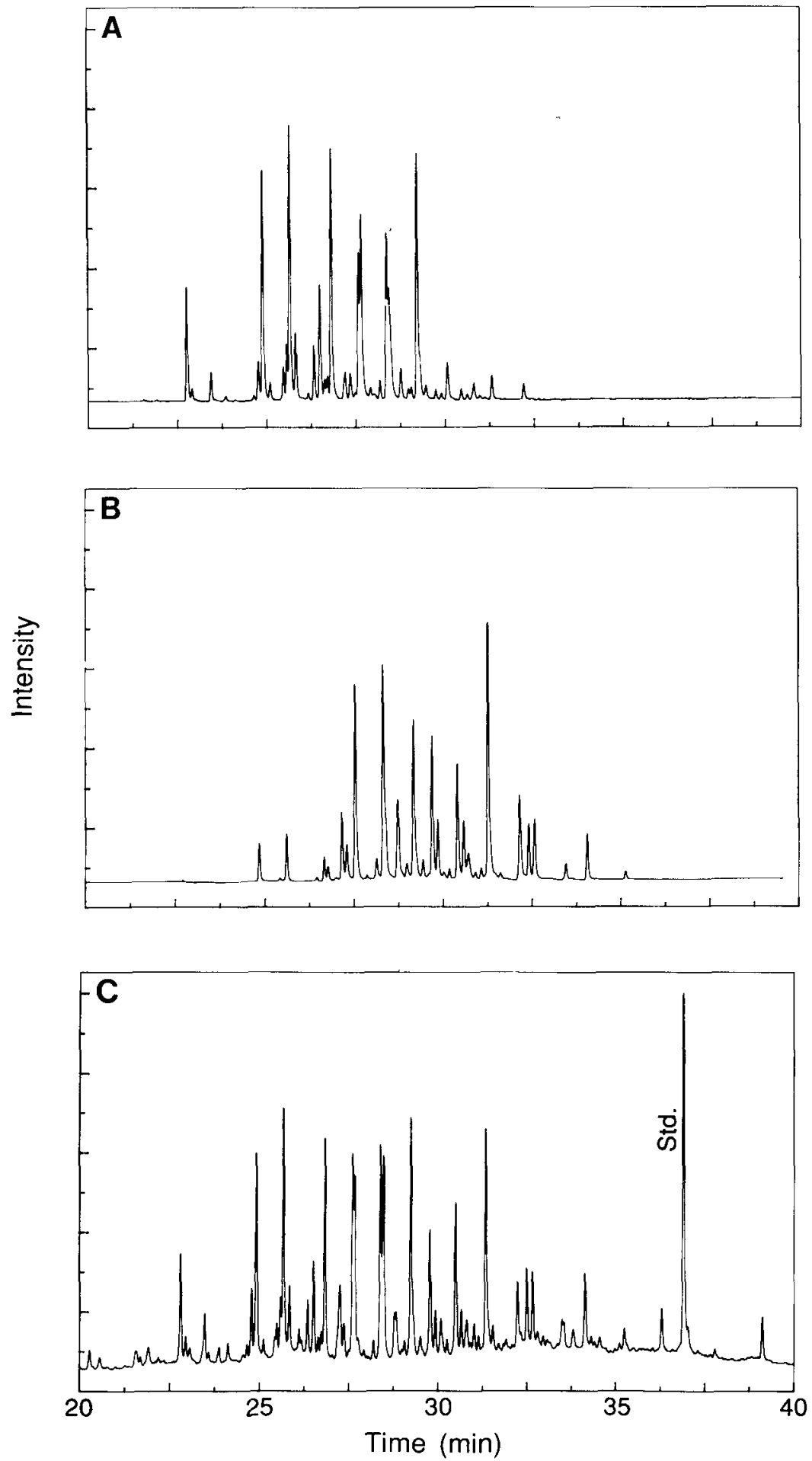

Fig. 1. GC-ELCD chromatograms of (A) Aroclor 1254, (B) Aroclor 1260, and (C) extract of effluent from an industrial facility. 

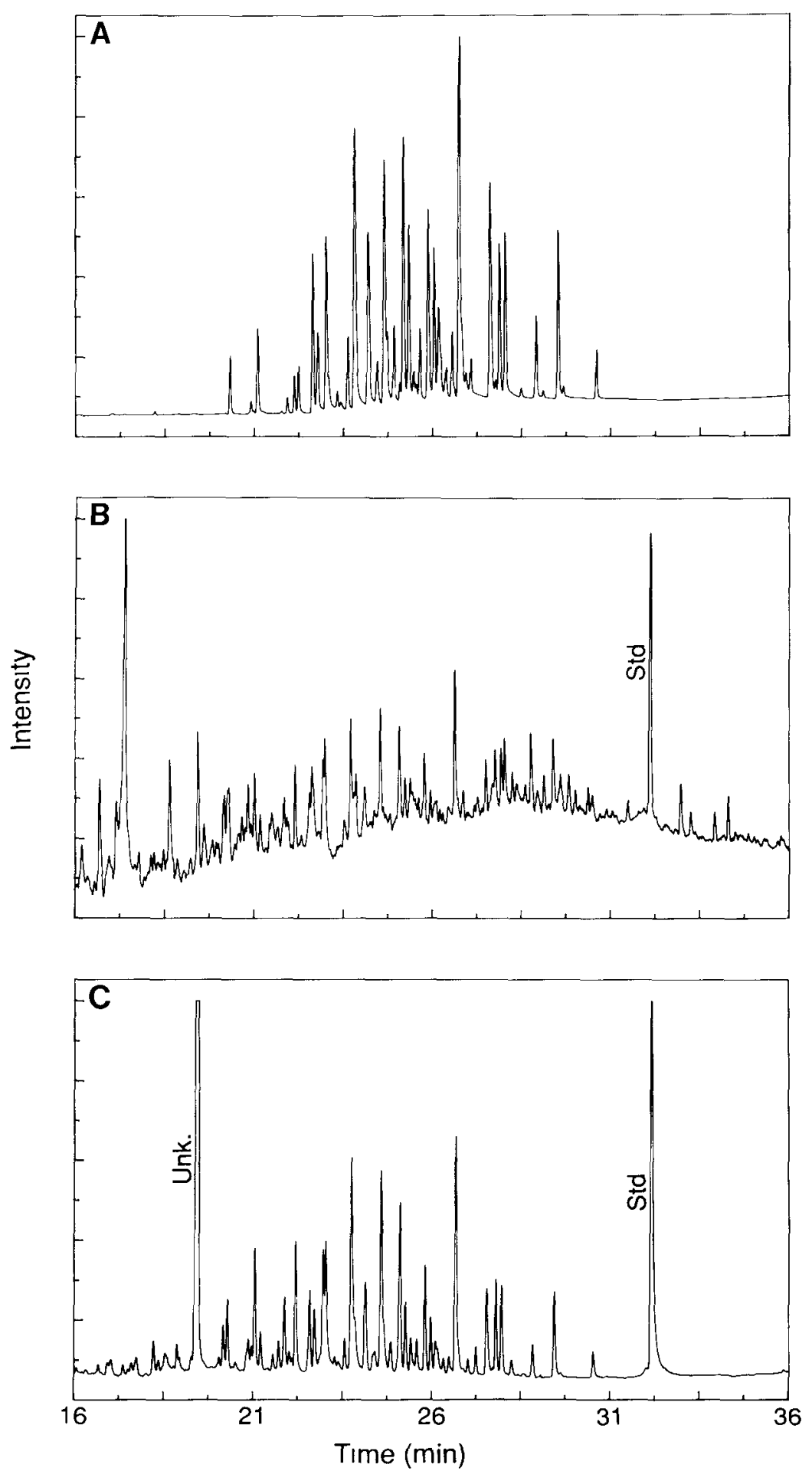

Fig 2 GC-ECD chromatograms of (A) Aroclor 1260, (B) extract of effluent from an industrial facility without removal of interfering compounds, and $(\mathbf{C})$ the same extract aftes cleanup by Florisil column chromatography. 
$\mu \mathrm{g} / \mathrm{L}$, and, therefore, the GC-ELCD with its higher selectivity and reduced sample preparation time was the preferred instrument. The GC columns were replaced more frequently when GC-ELCD was used because less pure samples were being injected. Typically a column could be used for 30 to 50 samples and their associated calibration runs. However, samples collected from the manufacturing-process water stream required purification on Florisil columns to prevent irreparable column damage and nonroutine maintenance of the detector. Results of spike recovery experiments indicated that the extraction procedure recovered approximately $70 \%$ of the Aroclor 1260 at the $1.0-\mu \mathrm{g} / \mathrm{L}$ level. Quantification was with respect to Aroclor 1260, although there was a mixture of Aroclors 1254 and 1260 present in the sample. This negated the problems caused by having to determine the ratio of Aroclors 1254 and 1260 present in the effluent and allowed convenient comparison with other published data. By necessity, therefore, the reported results are minimum effluent PCB concentrations. Potential adsorption of the $\mathrm{PCBs}$ to the glass containers was not accounted for, again meaning that the re- sults are conservative. The range of $\mathrm{PCB}$ concentrations in the analyzed effluents was from 0.1 to $1.0 \mu \mathrm{g} / \mathrm{L}$.

The high specificity for halogens provided by the GC-ELCD when combined with the elution profile of the PCB mixture provides a high degree of confidence as to the identities of the eluents. This is not absolute proof of identity, particularly in cases where mixtures of Aroclors are encountered, where the PCB mixtures have been subject to weathering, or where there are legal implications associated with the analyses, as is often the case where PCBs are concerned. In these instances, mass spectrometric identification is considered vital in establishing the identity of the compounds present. In this study, ECNCI-GC-MS was used to provide the necessary proof of identification. The specificity of this ionization technique was important because it was possible to analyze the effluent extracts directly, as they were analyzed by GC-ELCD, without additional cleanup. The sensitivity of ECNCI meant that full spectra could be obtained. Figure 3 shows spectra of a hexachlorobiphenyl (Fig. 3A) and a heptachlorobiphenyl (Fig. 3B) ob-

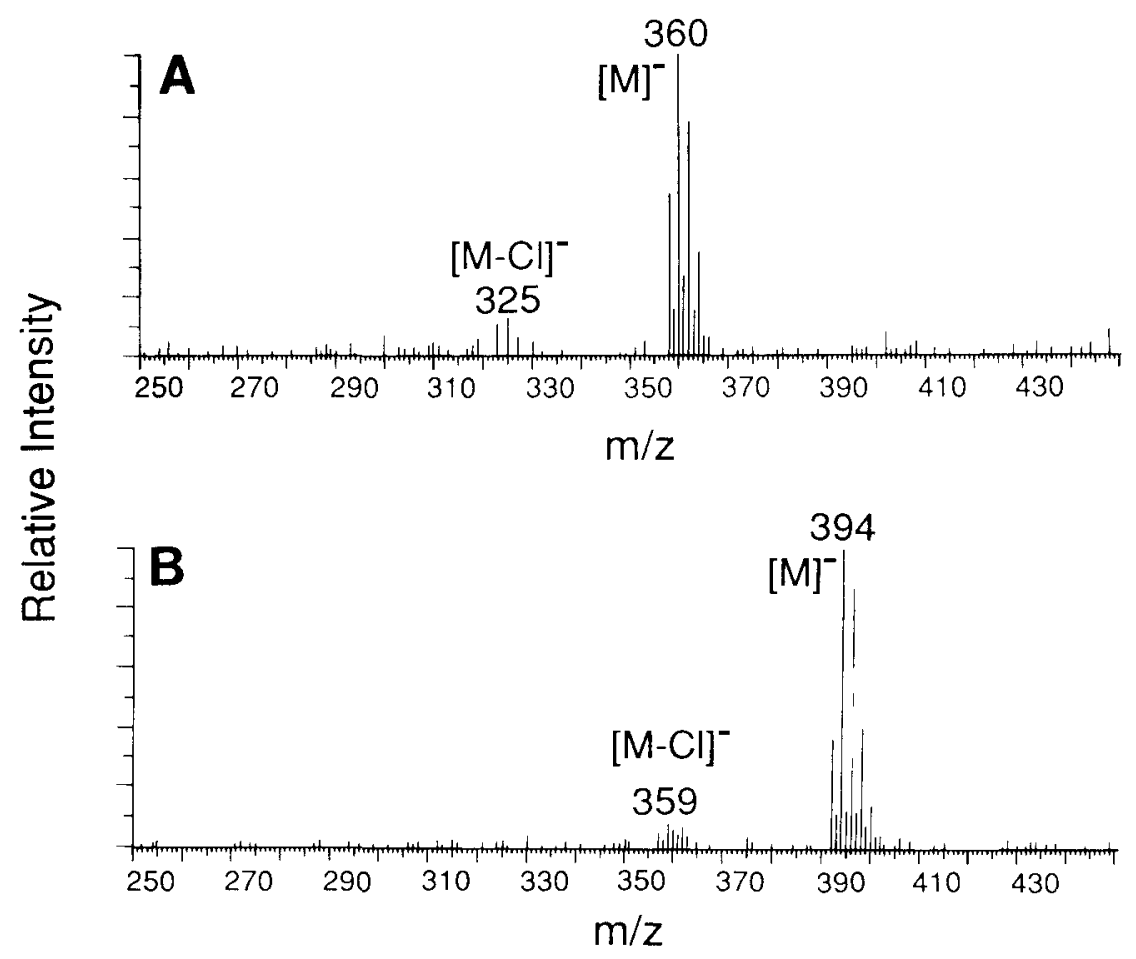

Fig. 3. ECNCI mass spectra of (A) a hexachlorobiphenyl and (B) a heptachlorobiphenyl, both from an effluent extract. 
tained from an effluent extract. These spectra were obtained from a sample in which the PCB concentration was $0.4 \mu \mathrm{g} / \mathrm{L}$. Good quality spectra could be obtained for the major PCB congeners even at the lowest observed concentrations. In addition to the full spectra, mass chromatograms were ex- tracted from the MS data and compared with similar chromatograms obtained from Aroclor 1260. Figure 4 shows such a comparison for the $m / z 360$, $m / z 394$, and $m / z 430$ ions, which are the major ions in the molecular ion clusters of hexachlorobiphenyl $[\mathrm{M}+2]^{-}$, heptachlorobiphenyl $[\mathrm{M}+2]^{-}$,
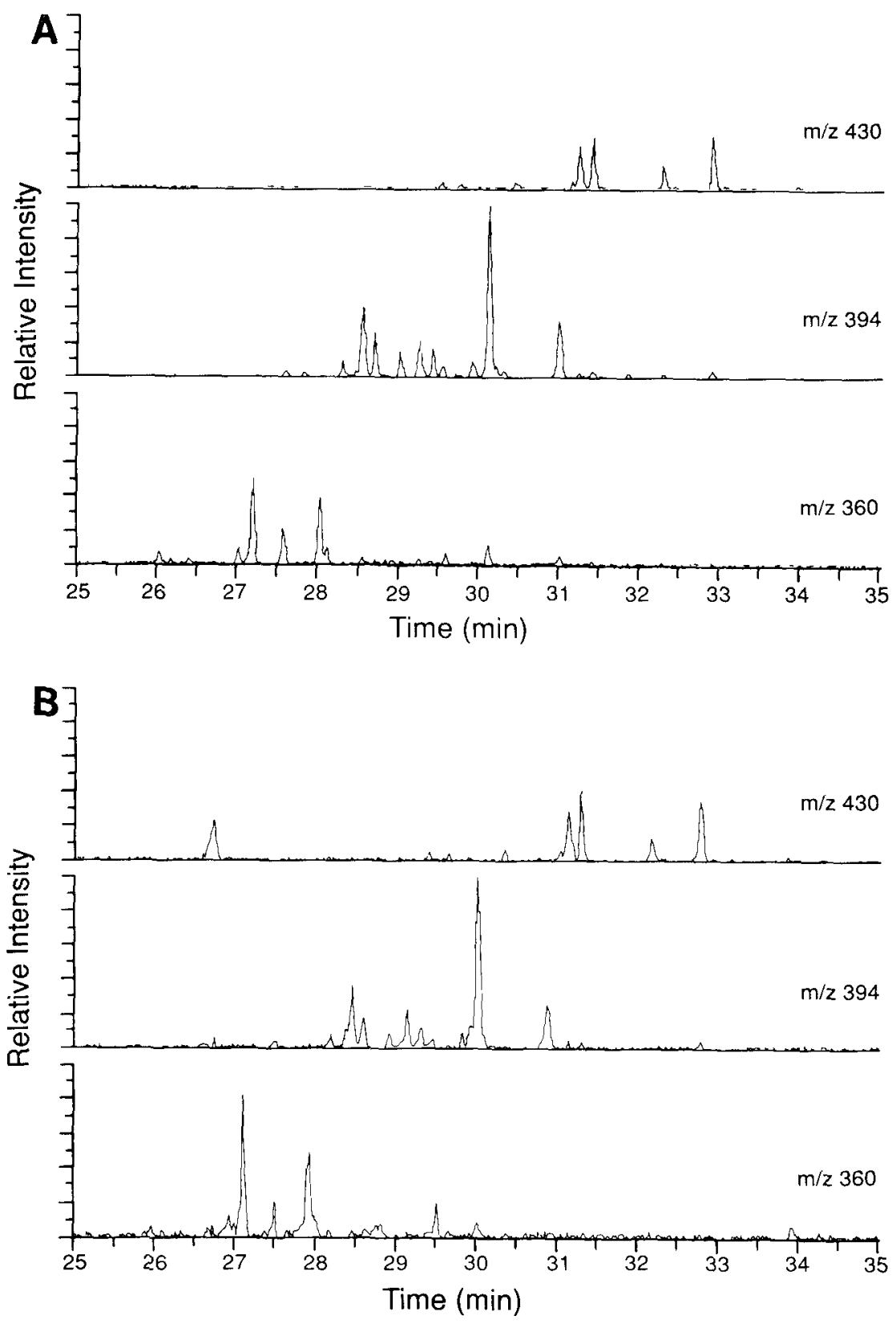

Fig. 4. Mass chromatograms of $m / z 360, m / z 394$, and $m / z 430$ ions of hexa- $[\mathrm{M}+2]^{-}$, hepta- $[\mathrm{M}+2]^{-}$, and octachlorobiphenyls $[\mathrm{M}+4]^{-}$, respectively; (A) Aroclor 1260 and (B) extract of industrial facility effluent. 
and octachlorobiphenyl $[\mathrm{M}+4]^{-}$. Figure $4 \mathrm{~A}$ is from Aroclor 1260, whereas Figure 4B was obtained from an environmental sample extract.

The result of the evaluation of the analytical techniques described above was that a combination of quantification by GC-ELCD and identity confirmation by ECNCI-GC-MS was the best approach to the analysis of environmental samples when some of the ultimate sensitivity of the GCECD could be sacrificed for the increased specificity and improved sample turnaround time afforded by the GC-ELCD.

An example of the use of the GC-ELCD and ECNCI-GC-MS pairing was in monitoring the $\mathrm{PCB}$ content of effluents from an industrial facility over a six-week period as efforts were made to remove the $\mathrm{PCBs}$ from the site. Over this period PCB concentrations in the effluent dropped from an average of 0.6 to $0.1 \mu \mathrm{g} / \mathrm{L}$. The volume of effluent from the wastewater treatment plant ranged from 6 to 49 million liters per day, resulting in output from the plant into the environment of approximately 1 to $31 \mathrm{~g} / \mathrm{d}$ PCBs. The total output of $\mathrm{PCBs}$ for the monitored period was approximately $450 \mathrm{~g}$. A plot of the PCB output from the plant is shown in Figure 5. The combination of the two techniques, with the simple sample preparation, meant that quantification and identification of the PCBs could be made within hours of sample receipt and that a real-time monitoring of the site could be maintained. There was no evidence, obtained by analysis of the river water constituting the intake supply to the complex, that the industrial site was being contaminated by incoming PCBs. Therefore, all the PCBs that were allowed to enter the natural environment via the effluent water were apparently attributable to the plant site.

Acknowledgement-The Virginia Water Control Board is acknowledged for supplying the data on the volume of effluent from the industrial facility.

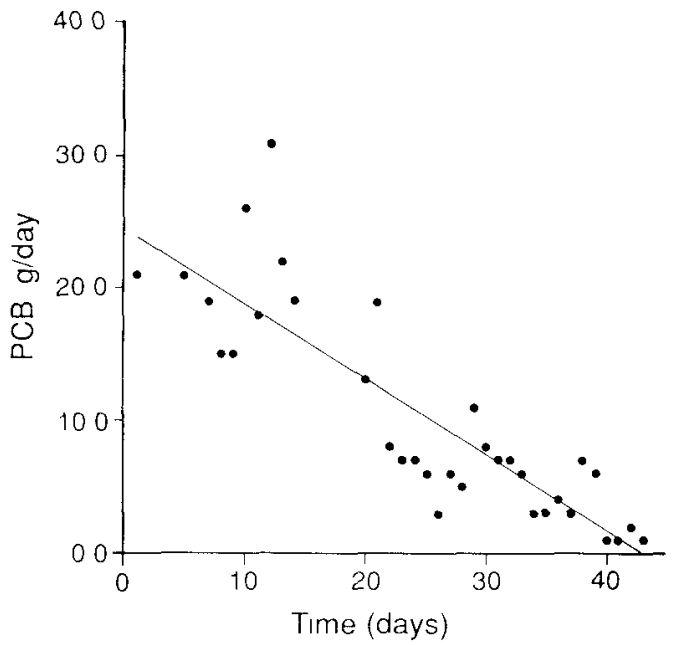

Fig. 5. Estimated output of PCBs, expressed as Aroclor 1260 , from an industrial facility over a 43-d monitoring period. Equation for the regression is $y=-0.57 x+24.5$, $r=-0.86$.

\section{REFERENCES}

1. Waid, J.S., ed. 1986. PCBs in the Environment, Vols. 1-3. CRC Press, Boca Raton, FL.

2. Smith, A.B. and D.P. Brown. 1986. Polychlorinated biphenyls in the workplace. In J.S. Waid, ed., PCBs in the Environment, Vol. 3. CRC Press, Boca Raton, FL, pp. 63-82.

3. Mullin, M.D., C.M. Ponchini, S. McCrindle, M. Romkee, S.H. Safe and L.M. Safe. 1984. High-resolution PCB analysis: Synthesis and chromatographic properties of all 209 PCB congeners. Environ. Sci. Technol. 18:468-476.

4. Edstrom, R.D. 1989. PCB congener analysis with Hall electrolytic conductivity detection. Ph.D. thesis. Virginia Institute of Marine Science, College of William and Mary, Gloucester Point, VA.

5. Budzikiewicz, H. 1986. Negative chemical ionization (NCI) of organic compounds. Mass Spectrom. Rev. 5:345-380.

6. U.S. Environmental Protection Agency. 1982. Methods for organic analysis of municipal and industrial wastewater. EPA 600/4-82-057. Cincinnati, $\mathrm{OH}$. 